\title{
The Effect of Implementing Panel Discussion on Speaking Skill of Iranian Intermediate EFL Learners
}

\author{
Mazyar Safarnejad \\ English Translation Department, Lahijan Branch, Islamic Azad University, Lahijan, Iran \\ Iraj Montashery \\ English Translation Department, Lahijan Branch, Islamic Azad University, Lahijan, Iran
}

\begin{abstract}
Using practical vocabularies and phrases plays a prominent role in developing speaking skill. The current research was designed to analyze the effect of implementing panel discussion on speaking skill of Iranian intermediate EFL learners. It was carried out at Ghasedak language institute in Astara among 70 intermediate male learners with the age range of 16-24 through a quasi-experimental research. The participants were assigned into two groups. One experimental group and the other labeled as control group. First, the pretest was administered to each group. The test was taken from the book "American File". At the end of 10 weeks, a posttest of speaking was given to both experimental and control group. Then learners' accuracy in simple past, simple present and present perfect and their fluency in using practical vocabularies and phrases were assessed. Results showed that teaching speaking based on panel discussion through CLT had a significant effect on learners' speaking skill.
\end{abstract}

Index Terms - panel discussion, speaking skill, CLT, turn-taking

\section{INTRODUCTION}

Panel discussion is a kind of discussion where members of particular group talk about a topic from divergent perspective in front of audiences. They criticize an issue, try to solve problem through argumentation and brainstorming of ideas. (Stojkovic, N, 2015). Dillon (1994) has clarified the participants of panel discussion discuss and talk about an issue which is a question for them. In fact, in this process, people learn how to communicate with each other and enable them to achieve a high level of consciousness and activity (Schein, 1993;"stojkovic. N (2015)").

Students learn how to talk to each other in a turn taking conversational democracy. (Abdullah \& Krishnan, 2013). As a matter of fact ,panel discussion trains student to concentrate on their Social Surrounding and setting of others who are listening .(Abdullah \& Krishnan ,2013).It can help learner to improve his speaking ability with participating in interaction and can help those are reluctant to engage themselves in discussion.(Riasati \& Nordin,2011).

Student-Centered approach is one of the Practical Procedure which is used in panel discussion. Teacher can be moderator and facilitator in the course of the class and can reach the goal of improving the students speaking ability (Abdullah \& Krishnan, 2013). Furthermore, this can help learners to be autonomous learners but with the cooperation of the peers. peer review helps learner to be active in their learning. (Lui and Carless, 2006) . Thus, learners find Propensity to focus on their own objective views.

The role of communicative approach can be enhanced. Congman (2013) wrote that, The highly methodology of ELT was disagree with the locally d teacher-centered approach system where the authority of the teacher plays prominent role. It is not acceptable that teaching should be stabile. Illustrative alteration in teaching methodology can cause a total decline in language teaching. ESL/ EFL necessarily take a cross-national and multi-cultural aspect, which has to consider local needs and socio-economic conditions. Researchers and other stakeholders are keen to know its efficacy in Southeast Asian countries. Perception of the teacher from the theory and practice of CLT and rational utilization of this method in panel discussion play important role. Panel discussion is proper with language learning because it can prepare language learners to have self confidence and participatory democracy. Studies from Weikel \& Mangram (1994) and Larson (2000) have examined the unique nature of discussion in general. Those studies represent that there are many types of discussion that are different in purpose, format and content. For this paper, the authors concentrate on students' perceptions of participating in panel discussion in the English language lesson. (As cited in Abdullah and Krishnan, 2014)

Panel discussion is a replacement to the typical student-centered assignments that make students to react to online postings where they have a lot of reaction time before giving response. Moreover, students' responses are rather difficult to obtain especially when they are not able to express their thoughts clearly because, they are shy. According to Riasati and Nordin (2011) language learners that feel they have lack of proficiency to communicate well would be more hesitate to begin communicating or be involved in communication. Having quick response in real life is crucial in 
different examples, therefore, panel discussion is an excellent way to instruct students to stay attentive and serious to the topic at hand because they need to "support their opinions with evidence, where their idea are subject to challenge by their classmates as well as the teacher, and where the teacher's thoughts are equally open to criticism" (Engle \& Ochoa, 1988). This encourages language learners to participate and keeps students on their toes as the audience (their interlocutors) can ask questions for clarification. (As cited in Abdullah and Krishnan, 2014).

As mentioned by Cazden (1988), "social aspects" of the classroom together with cognitive ability are practiced in the course of discussions. A rational and practical understanding and sensitivity of the topic by the panelists is important as their peers from the audience will share various views from those of the panelists and this is when "social aspects" of panel discussion come into play and become prominent. Panel discussion teaches students to be aware about their social surroundings and settings of others who are listening. Thus, the objectives of this study are to identify students' realization of Panel Discussions and to examine their perception on peer review and feedback by classmates for a Panel Discussion. (As cited in Abdullah and Krishnan, 2014)

\section{A. Why Panel Discussion?}

Group tasks have tendency toward the social interaction in second language. Interactional competence, Kramsch (1986) conceptually attributed to Vygotskys (1978) sociocultural theory. He argued that successful interaction happens within internal context that is built through effort of interactional partners (p.367).

Lowman (1987) believed that two types of teacher-student interaction are sometimes called discussion. In one, the instructor lets the learners to modify substance and inquire for ideas on relevant issue. Moreover, teacher asks some questions requiring particular knowledge. As a matter of fact, student-initiated questions are prominent in discussion classes based upon their requirements and this matter help students in order to find the ability to speak spontaneously and at the moment.

Gage and Berliner (1988) mentioned that learners can practice expressing themselves clearly and accurately and learn the procedure of rational criticizing and evaluating rationally. Prominent matter in panel discussion is critical thinking. Simpson (2012) believed that, learner needs help in a in a reflective way with rational type of thinking which lead them directly to do things. According to Gardner and jewler (1992), in addition to problem solving, critical thinking helps students to distinguish unfamiliar from familiar and strange from unclear matter within practical practice, such a way that, they realize the practices which lead them to think rationally. (Van Lier \& Corson, 1997, p. 245).

Proficiency is the ability which allows learners to use language in real world in an automatic communication in acceptable and proper manner to native speakers of the language. Students with high proficiency find the ability in themselves to speak regardless of where and when or how the language was accumulated, such a way that, it is not important context must or must not be familiar; the evaluation of proficiency is not only based on content of a particular curriculum that has been taught or learned. In fact, learners find sufficient evidence for their thoughts and share with the class their ideas in a communicative way. As a result, language proficiency can be improved within panel discussion based on the levels which they are present in. language proficiency represents our competency in foreign language communication.

Panel discussion has some educational purposes because it is a determined form of learner talk that will help to the dynamic of the classroom. As a matter of fact, panel discussion needs language learners to talk with high cognitive and affective level about the related topic. Students speak with each other and use turn-taking in their conversation. Panel discussion is somehow similar to free discussion, but it is existed in a dynamic setting. Dillon (1994) has clarified that the topic which language learners are going to talk about, is a question for them. Their discussion consists of various suggestions over the topic." Discussion can be a good teaching method for learners to develop their thinking skills that effectively allow them be able to analyze, operate and interpret information rather than focus again and again on details and facts. As a matter of fact, learners are the active receivers of information. Faust \& Paulson (1998) demonstrate that Panel Discussions will be effective if it concentrates on all members in the class rather than individual. (As cited in Abdullah and Krishnan, 2014)

\section{B. Student-centered Learning}

Student-centered learning is a practical approach which involves learners in speaking and conversation process by utilizing panel discussion. This helps the instructor to achieve the goal of improving the students' speaking ability. Student-centered learning requires planning, teaching, and assessment that concentrate on the abilities and requirements of the learners on how they learn, how they engage with their learning and peers and what they experience. In fact, student-centered learning is a classroom environment of shared knowledge and shared authority between the students and the teacher, with the teacher giving freedom to the students to experiment with their own learning. Student-centered models are derived from the theoretical perspectives of John Dewey and many other twentieth century progressive educators as well as on the theoretical perspective proposed by modern developmental and cognitive psychologists. In these views, it is believed that the idea of knowledge is not objective and fixed, but is somewhat personal, cultural and social. The students, through experience and discussion are able to construct and realize meaning (Arends, 2004). Arends (2004) also noted that a teacher requires many approaches in the classroom in order to meet learning objectives with a diverse population of students. The use of a single method or approach is no longer sufficient. There are enough choices for a teacher to select from the approaches that best help the teacher to achieve the objectives or the models that 
can be used to promote the students motivation, achievement and involvement. (As cited in Abdullah and Krishnan, 2014)

\section{METHOD}

This study is a quasi-experimental study with two individual groups of students. Because of assessing more reliable, internal validity and avoiding random assignment, this kind of research was done. Thus, Learners are given pretest in order to achieve comparability of the groups prior to their treatment and posttest to analyze the effect of treatment. The research was done at Ghasedak institute in Astara.

\section{A. Participants}

Based on OPT, 70 participants were chosen randomly from 90 intermediate students of Ghasedak institute in Astara who have been studying English there for at least two years. They were divided into two individual groups of 35 members. These two groups labeled as experimental group and control group. The participants were in the age range of 16-24 and all were males with Persian mother tongue. The first experimental group taught English conversation through the implementation of panel discussion in CLT based method with Mat Clark book, however the control group taught English conversation through American File books.

\section{B. Research Instrument}

\section{Oxford Placement Test (OPT)}

For having two homogenous groups, Oxford Placement Test (OPT) was applied.

The test contained 90 questions which were divided into 80 grammar and 10 vocabulary questions. At the end students were asked for accomplishing a speaking task for the evaluation of learners' competence in tenses and vocabulary, and phrases. 90 minutes was the specified time for answering to the questions. Finally, 70 students were chosen as intermediate level students on the basis of the Oxford Proficiency Test.

\section{Pretest and Posttest}

According to J Ventura, (2013) the prominent assessment of speaking is the oral interview. Rather than OPT, some descriptive questions based on different topics were asked like: Time Management, Advertisements, University, Television and Radio, Birds, History, Fruits, school, free time, Own idea, Bus and Taxi, Politeness, Daily Routine, Work/Study, Family. This interview was used as pretest and posttest in this study based on Mat Clark.

\begin{tabular}{|c|c|c|}
\hline Session & Topics & Source \\
\hline 1 & Advertisements & Mat Clark \\
\hline 2 & University & Mat Clark \\
\hline 3 & Television & Mat Clark \\
\hline 4 & Flats or Accommodation & Mat Clark \\
\hline 5 & School & Mat Clark \\
\hline 6 & Free time & Mat Clark \\
\hline 7 & Own idea & Mat Clark \\
\hline 8 & Time management & Mat Clark \\
\hline 9 & Daily Routine & Mat Clark \\
\hline 10 & Work or study & Mat Clark \\
\hline 11 & Sum up and panel discussion & 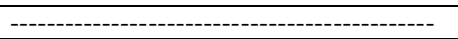 \\
\hline 12 & Different cultures & American File \\
\hline 13 & Learning new language & American File \\
\hline 14 & Seasons & American File \\
\hline 15 & Foods & American File \\
\hline 16 & Customs & American File \\
\hline 17 & Traveling & American File \\
\hline 18 & Entertainment & American File \\
\hline 19 & Appearance & American File \\
\hline 20 & Sum up and panel discussion & -------------------------------------------------- \\
\hline
\end{tabular}

Figure1. Topics and sources for every session

\section{Treatment of the Study}

This study was administered in Winter 2019. It had a quasi- experimental design. Seventy intermediate EFL students were chosen as the participants of this study based upon their performance in the Oxford Placement Test (OPT), Then, they were randomly divided into two groups which were known as experimental and control group. Next, the pretest was designed. It was an interview piloted with a reliability index of 0.78 . Then, the experimental group was treated by the implementation of panel discussion in speaking ability of intermediate learners.

The control group treated by engaging American File books for teaching English conversation. The book which was used as textbook for the experimental group is Mat Clark. After 20 sessions in 10 weeks, the posttest was designed to evaluate the learners' advancement. The pretest and posttest questions were alike. We used two teachers for teaching during the term to control fluency and accuracy of the learners. However, the students' answers were assessed in 
vocabulary, , comprehension; but, Accuracy in pronunciation, simple present, simple past and present perfect was the prominent matter which we were looking for.

\section{Data Analysis}

The reliability of 60 items of the multiple choice Oxford placement test was approximated through a pilot study on 15 EFL learners. Moreover, the index of reliability was interpreted according to the reliability standards suggested by Barker, Pistrang, and Elliott (1994).

TABLE. 1

SUGGESTED StANDARDS (ADOPTED From BARKER, PISTRANG, AND ElliOTT, 1994)

\begin{tabular}{ll}
\hline Interpretation of the findings & Reliability indices \\
\hline Good & .80 \\
Acceptable & .70 \\
Marginal & .60 \\
Poor & .50 \\
\hline
\end{tabular}

The determined value of Cronbach alpha for the multiple-choice OPT equalled .796, which was acceptable based on the reliability standards suggested by Barker, Pistrang, and Elliott (1994). The results are presented in Table.2

TABLE. 2

RELIABILITY STATISTICS FOR THE OPT TEST

\begin{tabular}{lcll}
\hline & Cronbach's Alpha & N of Items & N of sample \\
\hline OPT test & .796 & 60 & 15 \\
\hline
\end{tabular}

To make certain that the main subjects of the study were approximately at the same level of language proficiency, the Standardized Oxford quick placement test (version 1) was given to $(n=90)$ EFL learners who were studying English as foreign language at a language institute in Astara. The participants took three sections that included items related to grammar, vocabulary and reading comprehension with a maximum possible score of 60 points. Thirty students whose score fell within the range 37-47 were selected as the main sample for the present study. Based on Oxford quick placement test direction, scores within the range of 10-17 are considered Beginners, 18-27 3 (Elementary), 28-36 (Lower intermediate), 37-47 (Upper intermediate), 48-55 (Advanced), and 56-60 (very advanced). The results of the OPT test for 90 students is available in the following table:

TABLE. 3

\begin{tabular}{ll}
\multicolumn{2}{l}{ STATISTICS FOR THE GENERAL ENGLISH PROFICIENCY TEST } \\
\hline \multicolumn{2}{l}{ OPT Statistics } \\
\hline OPT scores \\
\hline $\mathrm{N} \quad$ Valid \\
\cline { 2 - 2 } Missing & 90 \\
\hline Mean & 0 \\
Std. Error of Mean & .80 .9500 \\
Median & 38.0000 \\
Mode & $40.00^{\mathrm{a}}$ \\
Std. Deviation & 7.97448 \\
Variance & 63.592 \\
Skewness & -.449 \\
Std. Error of Skewness & .269 \\
Kurtosis & -.058 \\
Std. Error of Kurtosis & .532 \\
Range & 38.00 \\
Minimum & 27.00 \\
Maximum & 55.00 \\
Sum & 2956.00 \\
a. Multiple modes exist. The smallest value is shown
\end{tabular}

Table.3 showed the results of group statistics and numerical information for the OPT test scores which was administered for selecting homogeneous sample out of $(n=90)$ EFL students. Measures of central tendency including the mean, the median, the mode and measures of dispersion namely the variance, and the standard deviation together with measures of distribution such as Skewness and Kurtosis were displayed for the OPT test. For the present study, the main sample included 70 intermediate participants who were selected based on Oxford placement test direction in order to select a group of intermediate EFL learners. Hence, the above descriptive statistics was informed for the $(n=70) E F L$ students.

After homogenizing the sample population for the purpose of the present study, it was important to calculate the speaking interview test reliability. The reliability of 30 items of the speaking pre-test was approximated through a pilot study on 20 EFL learners. Moreover, the index of reliability was interpreted according to the reliability standards suggested by Barker, Pistrang, and Elliott (1994). 
TABLE. 4

RELIABILITY STATISTICS FOR THE SPEAKING PRE-TEST

\begin{tabular}{lccl}
\multicolumn{4}{c}{ RELIABILITY STATISTICS FOR THE SPEAKING PRE-TEST } \\
\hline & Cronbach's Alpha & N of Items & N of sample \\
\hline Speaking pre-test & .780 & 30 & 20 \\
\hline
\end{tabular}

The same test was applied for the post-test of speaking which included the same number of items with the same questions as the post-test. The determined value of Cronbach alpha for the speaking pre-test equaled 0.780 which was acceptable based on the reliability standards suggested by Barker, Pistrang, and Elliott (1994).

TABLE.5

TESTS OF NORMALITY

\begin{tabular}{lllllll}
\hline & Group & \multicolumn{2}{c}{ Kolmogorov-Smirnov } & & \multicolumn{2}{c}{ Shapiro-Wilk } \\
& & Statistic & df & Sig. & Statistic & df \\
\hline \multirow{2}{*}{ Score } & Posttest experimental group & .147 & 35 & .097 & .904 & 35 \\
& posttest control group & .144 & 35 & .114 & .940 & 35 \\
\hline
\end{tabular}

Before running the descriptive statistics on the pretest and posttest performances of the two groups, it was necessary to decide upon the normality of the obtained data. As the table.6 shows, they are normal groups with the following characteristics. To recognize that, the data gathered were normal a Kolmogorov was run. Following prominent level of the first group scores for the class who had a treatment, the number was obtained sig $=0.097>0.05$ which is larger than 0.05 and proves the normality of our data. The control group received a significance level of 0.114 which is again larger than 0.05 confirming that the data has the characteristics of a normal population.

TABLE.6

DESCRIPTIVE STATISTICS FOR THE GROUPS PRE-TEST

\begin{tabular}{llllll}
\hline Group Pretest Statistics & & & & & \\
\hline \multirow{3}{*}{ pretest scores } & groups & N & Mean & Std. Deviation & Variance \\
& control & 35 & 14.57 & 2.431 & 5.909 \\
& experimental & 35 & 14.17 & 2.451 & 6.006 \\
\hline
\end{tabular}

Table. 6 showed that there are not lots of differences between the means in the pretest of the experimental group and control group. The mean score for the control group equaled 14.57 while the experimental group received a mean score of 14.17. Moreover, it is revealed that the performance of the control group was more homogenous compared to the experimental group since the standard deviation of scores equaled $(\mathrm{SD}=2.431)$ for the control group. It is evident that performance of both control and experimental group did not differ greatly at the beginning of the study. Additionally, both groups had almost the same performance in terms of homogeneity of scores regarding their pretest performances.

TABLE. 7

DESCRIPTIVE STATISTICS FOR THE GROUPS POST-TEST

\begin{tabular}{llllll}
\hline Group Posttest Statistics & & & & & \\
\hline \multirow{3}{*}{ posttest scores } & Groups & N & Mean & Std. Deviation & \\
& Control & 35 & 15.60 & 2.554 & 6.524 \\
& Experimental & 35 & 17.40 & 2.078 & 4.317 \\
\hline
\end{tabular}

Table.7 shows descriptive statistics that was run on the post-test performances of the groups at the end of the study. The mean score of the experimental groups (17.40) was significantly higher than their pre-test performance while the control group did not reveal a considerable improvement (15.60). Regarding the homogeneity of the performances between groups, the standard deviation of the experimental group was lower ( $\mathrm{SD}=2.078$ ) which shows the scores were more homogenous in the posttest of the experimental group. It can be derived that the speaking performance of the experimental group improved which might be due to the treatment through panel discussion. In general, the experimental group performed better after the treatment based on the descriptive analysis of data.

\section{E. Inferential Analysis of the Data}

In order to answer the research question, i.e., whether teaching speaking through panel discussion has an effect on Iranian male intermediate EFL learners' speaking performance, an independent samples T-test was run to the results of the posttest scores of the speaking test for both control and experimental groups. This was run to examine the differences between the two groups in terms of their English speaking performance at the end of the study. The results are presented in Table .8 
TABLE.8

INDEPENDENT SAMPLES TEST FOR COMPARING POSTTEST OF BOTH GROUPS

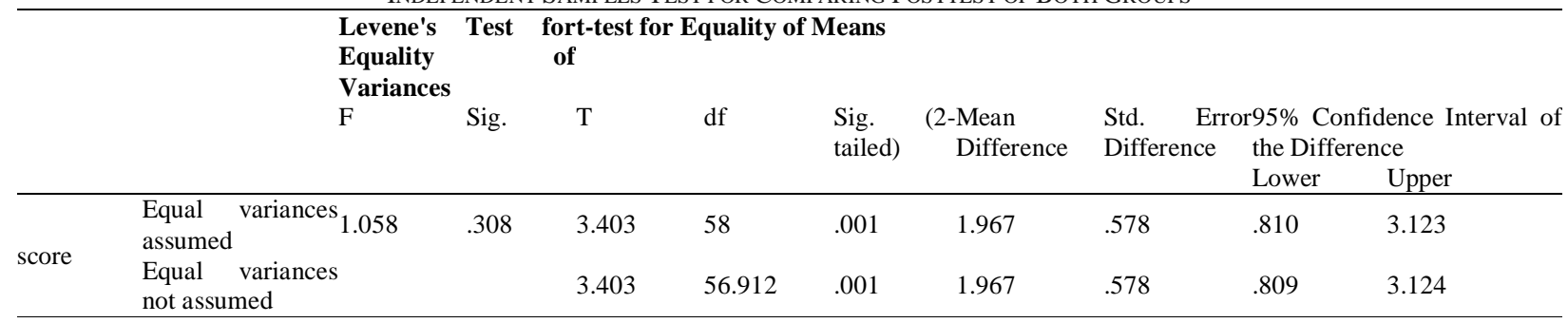

Levene's test was utilized for determining equality of variances that means whether the variation of scores was the same for both groups. Since the p value is larger than (.05), the first line of the Table 4.8 was reported. In other words, Equal variance assumed line was taken into account. The amount equaled 1.058 and this confirms the equality of variances.

The results represented that there was a statistically prominent difference in scores for experimental group and control groups $t=3.403$, sig $(.001)<.05)$. This outcome confirmed that teaching speaking through panel discussion for the experimental group has had an effect which helped the language learners in the experimental group to outperform in the speaking test. Learning speaking by the help of CLT approach improved the speaking ability of the participants in the experimental group. As a result, the null hypothesis that panel discussion has no effect on improvement of speaking skill of Iranian male intermediate EFL learners', was rejected.

In order to investigate students' progress within groups, another statistical procedure was run. To find out the subjects' possible progress in pre-test and post-test, paired t-tests were also run. They are shown in Tables 4.9, and 4.10.

TABLE.9

PAIRED SAMPLES STATISTICS

\begin{tabular}{llllll}
\hline \multicolumn{2}{l}{ Paired Samples Statistics } & Mean & $\mathrm{N}$ & Std. Deviation & Std. Error Mean \\
\hline \multirow{2}{*}{ Pair 1 } & Control group pretest & 14.57 & 35 & 2.431 & .28268 \\
& Control group posttest & 15.69 & 35 & 2.554 & .31571 \\
\hline \multirow{2}{*}{ Pair 2 } & Experimental group pretest & 14.17 & 35 & 2.451 & .35973 \\
& Experimental group posttest & 17.40 & 35 & 2.078 & .36893 \\
\hline
\end{tabular}

According to table.9, the performance of the control group has improved slightly since their pre-test performance mean score equalled 14.57 and changed to a mean score of 15.69 at the end of the study. On the other hand the experimental group has had a better performance than that of the control group since their pre-test performance mean score was 14.17 and improved to a mean of 17.40 after the treatment.

TABLE. 10

PAIRED SAMPLES TEST FOR SPEAKING TEST

\begin{tabular}{|c|c|c|c|c|c|c|c|c|c|}
\hline & & \multicolumn{5}{|c|}{ Paired Differences } & \multirow[t]{3}{*}{$\mathrm{T}$} & \multirow[t]{3}{*}{ df } & \multirow{3}{*}{$\begin{array}{l}\text { Sig. (2 } \\
\text { tailed) }\end{array}$} \\
\hline & & \multirow[t]{2}{*}{ Mean } & \multirow[t]{2}{*}{ Std. Deviation } & \multirow[t]{2}{*}{$\begin{array}{l}\text { Std. Error } \\
\text { Mean }\end{array}$} & \multicolumn{2}{|c|}{$\begin{array}{l}95 \% \text { Confidence Interval } \\
\text { of the Difference }\end{array}$} & & & \\
\hline & & & & & Lower & Upper & & & \\
\hline : & $\begin{array}{l}\text { Control group pretest } \\
-\quad \text { control group } \\
\text { posttest }\end{array}$ & -.478 & 1.238 & .2582 & -1.013 & .05726 & -1.85 & 22 & .077 \\
\hline$\stackrel{7}{*}$ & $\begin{array}{l}\text { Experimental group } \\
\text { pretest - experimental } \\
\text { group posttest }\end{array}$ & -1.91 & .949 & .1979 & -2.323 & -1.502 & -9.66 & 22 & .000 \\
\hline
\end{tabular}

As both tables in paired samples tests showed, both groups had a better performance compared to their pre-test performances. However regarding the statistical procedure of paired samples T-test, such a progress was statistically significant to the favour of the experimental group not the control group. This means that the experimental group provided a noticeable improvement as compared to the control group in the post-speaking evaluation.

\section{DISCUSSION AND CONCLUSION}

This chapter demonstrates the discussion and results of the study based on the previous chapter which represented that how panel discussion was helpful in improving speaking skill; some limitations of the study are explained and also these will be followed by further research and practical studies which would be helpful and suggested in this field. The main purpose of this research was to examine the effect of implementing panel discussion on speaking ability of intermediate EFL students. As it mentioned in previous section, students in both control group and experimental group did not differ greatly at the beginning of the study. Additionally, both groups had almost the same performance in terms of homogeneity of scores regarding their pretest performances, but after operating panel discussion the speaking performance of the experimental group improved through communicative language teaching. As it mentioned in chapter 
three, some topics implemented within Mat Clark source in experimental group such a way that learners shared some prominent phrases from each topic in every session; trying to convey their ideas by utilizing phrases, discuss in a group in front of audiences and let them to ask questions. At the end, posttest demonstrated that learners significantly improved through using panel discussion. So that, control group which was trained by American File book improved slightly. In addition to, panel discussion helps learners to break their silent period and do not be solitary in the course of the class. Thereby, as it mentioned in chapter two, instructors have prominent role in operating panel discussion, so that they should motivate learners to enhance their self-confidence and give them an opportunity to find the ability in themselves to communicate and using practical phrases purposefully. This details which were done in the class helped the experimental group performed better. For more clarification, the whole study includes five chapters, the introduction, literature review, methodology and procedure, data analysis which emanate from methodology, discussion and conclusion of carrying out the thesis, the discussion of findings and the conclusion of the work.

The primary purpose of this study was to see the effect of implementing panel discussion on speaking ability of intermediate EFL students. This study comes to the conclusion that panel discussion has a great effect on English conversation to Iranian intermediate EFL learners; as a matter of fact, students get in progress in terms of utilizing practical and useful vocabulary and phrases and also improves learners' speaking accuracy in present simple, Past simple and present perfect particularly.

The next prominent attribution of the representing panel discussion in the class is concentrating on student-centered approach and communicative language teaching. In fact, it's not only keep all the learners active in the class, but also it helps students in order to improve their discussion and writing skill by using take-notes and make it into cohesive writing as well.

As mentioned above, communicative language teaching approach was held in the class in the course of the term. So, Learners' responsibility and team work was enhanced; Based on this point that everybody is responsible for his own learning but with the cooperation of each other, students achieve in self-esteem and absolutely self-confidence which is one of the most important factors of learning a language. Within CLT, panel discussion was represented in the class, learners shared their ideas with other groups and audiences; here the effect of listening can be mentioned_learners and audiences' interacts with each other during the class.

This research was intended to investigate the effect of the implementation panel discussion on speaking ability of Iranian intermediate EFL learners. The results of the study represent that the experimental group which were under treatment of communicative language teaching within panel discussion performed particularly better than the control group in conversation ability. As a matter of fact, students in panel discussion could make progress in speaking through practicing the use of phrases for debating and discussing, questioning, argumentation, and rhetorical skills practice. Moreover, they realized the use of indirect questions, reported speech, conditional sentences, and passive voice. The study findings also represent that panel discussion helped learners to have critical thinking. Utilizing the panel discussion in English conversation can improve the students' self-esteem and confidence in order to have an active role in real conversations and helps those learners who are not active in the course of the class. It improves students' fluency and accuracy within using the simple present, simple past and also present perfect. The participants were students of Ghasedak institute in Astara.

At the end the learners perceived and found the learning of English language really pleasurable with the high enthusiasm for carrying out easily and successfully. This study implied the quotation of Douglas Brown which narrates teaching as a mean of taking care of student self-confidence as a pre-requirement of teaching any input.

\section{REFERENCES}

[1] Cazden, C. (1988). Classroom discourse the language of teaching and learning: Creative Education, vol.7 No.3

[2] Congman, R and Saeed, A. (2013). Communicative approach in teaching English as a foreign language: a case study of Pakistan. Porta Linguarum, pp. 187-203

[3] Faust, J and Paulson, R. (1998). Active learning in the college classroom: Journal on excellence in college teaching, 9 (2). 3-24.

[4] Kato,F (2000). Discourse approach to turn-taking from the perspective of tone choice between speakers: University of Birmingham, www.birmingham.ac.uk.

[5] Khoirul.A (2016). Panel discussion and the development of students' self-confidence: Journals English language teaching, vol. 9 No. 4.

[6] Krishnan, S. Abdullah, A. (2014). All for one: Using panel Discussion to improve proficiency through group work. Social and behavioral sciences, volume 123, p 225-231.

[7] Lier, V and Corson, p. (1997). Encyclopedia of language and education. P.245

[8] Riasati, MJ. N, Noordin. (2011). Antecedents of willingness to communicate: A Review of Literature, www.researchgate.net.

[9] Stojkovic, N. (2015). Vistas of English for specific purposes: Implementing panel discussion in ESP teaching, 293-303.

[10] Wood, J. (2011). communicative language teaching (CLT) and communication strategies (CSs): Theory and practice. www.semanticscholar.org, 231-240. 
Mazyar Safarnejad, born in Astara, Iran, August, 1997. Has a BA in English language and literature at Guilan University (2016) and got MA in teaching English as a foreign language TEFL at Islamic Azad University of Lahijan (2019).

Iraj Montashery has obtained his ph D degree in English literature from UPM with distinction. He is currently an assistant professor at Islamic Azad University of Lahijan. His main research interests are narrative studies, teaching English through literature and discourse-based teaching. 